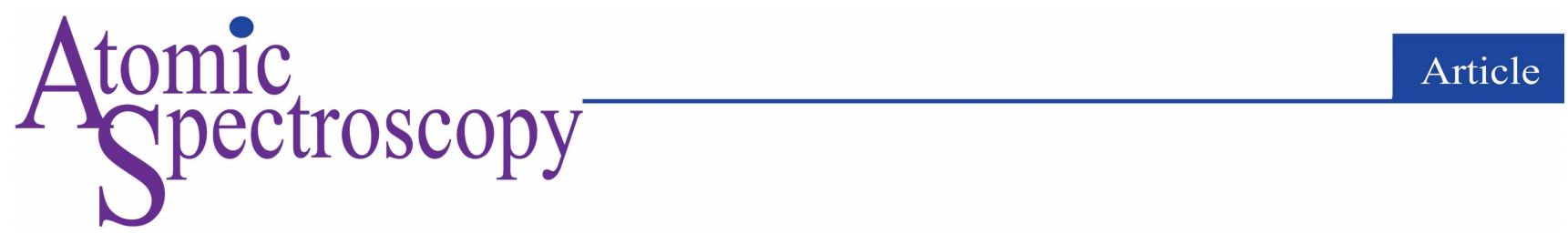

\title{
Continuous Online Leaching System Coupled with Inductively Coupled Plasma Mass Spectrometry for Assessment of Cr, As, Cd, $\mathrm{Sb}$, and $\mathrm{Pb}$ in Soils
}

\author{
Alastair Kierulf, ${ }^{\mathrm{a}}$ Michael Watts, ${ }^{\mathrm{b}}$ Iris Koch, ${ }^{\mathrm{c}}$ and Diane Beauchemin ${ }^{\mathrm{a}, *}$ \\ a'Department of Chemistry, 90 Bader Lane, Queen's University, Kingston, Ontario, K7L 3N6, Canada \\ bInorganic Geochemistry, Centre for Environmental Geochemistry, British Geological Survey, Nottingham, NG12 5GG, UK \\ 'Department Chemistry and Chemical Engineering, Royal Military College of Canada, 12 Verité Avenue, P.O. Box 17000 Station Forces, Kingston, ON, \\ Canada
}

Received: August 20, 2021; Revised: October 29 2021; Accepted: November 01, 2021; Available online: November 08, 2021.

DOI: $10.46770 / A S .2021 .827$

ABSTRACT: Incidental ingestion of soil containing $\mathrm{Cr}, \mathrm{As}, \mathrm{Cd}, \mathrm{Sb}$, and $\mathrm{Pb}$ has been attracting global attention as it can significantly impact human health. Many bioaccessibility methods have been developed to simulate the amount of contaminants extracted by gastrointestinal fluids following incidental ingestion. Although the continuous online leaching method (COLM) offers various advantages over conventional batch bioaccessibility methods, such as reduced analysis time, elemental source apportionment, and isotopic analysis, it has not yet been applied to soil and directly compared to validated, published methods. This study uses the COLM with simulated gastrointestinal fluids from the United States Environmental Protection Agency (US EPA), United States Pharmacopeia (USP), and unified bioaccessibility method (UBM) to measure the bioaccessibility of $\mathrm{Cr}, \mathrm{As}, \mathrm{Cd}, \mathrm{Sb}$, and $\mathrm{Pb}$ in NIST 2710, NIST 2710a, NIST 2711a, and BGS 102. When the US EPA gastrointestinal fluid was used, no significant difference was observed between the COLM bioaccessible + residual, aqua regia extraction, or certificate concentrations for all the elements and soils studied. Furthermore, COLM bioaccessibility was within the acceptable range of control limits and bioavailability (animal) studies for most reference materials. In addition, no statistically significant difference was observed between either the US EPA batch method or the stomach phase of the UBM batch method and the stomach stage of the COLM, indicating that the COLM could be incorporated into current bioaccessibility analyses to improve soil contamination characterization in the future.

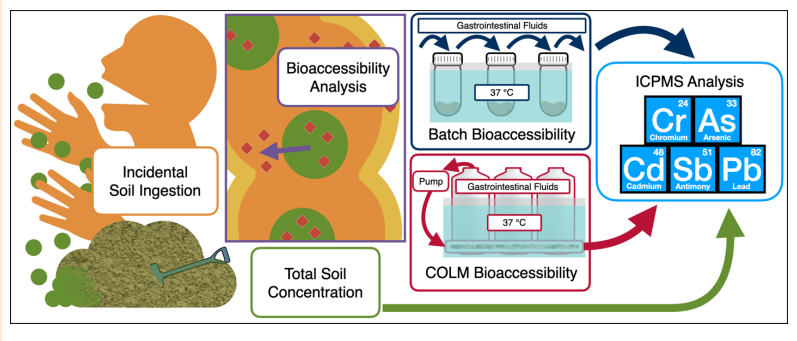

\section{INTRODUCTION}

$\mathrm{Cr}, \mathrm{As}, \mathrm{Cd}, \mathrm{Sb}$, and $\mathrm{Pb}$ can be toxic, carcinogenic, or have other neurological or adverse health effects, and therefore, their presence in soil can adversely affect humans, other animals, and the natural environment. ${ }^{1} \mathrm{Cd}$, for instance, can cause nephrotoxicity in humans. $\mathrm{Cr}$ and $\mathrm{Sb}$ have been observed to have adverse health effects in rats. $\mathrm{Pb}$ can cause neurotoxicity in children. As is a known carcinogen. ${ }^{1}$ In addition, $\mathrm{Sb}$ and $\mathrm{Cr}$ have been recognized as risk drivers in human health risk assessment. Various methods have been validated to determine $\mathrm{As}, \mathrm{Pb}$, and $\mathrm{Cd}$ in soils. Some soil types are naturally rich in one or more of these elements, while others can be contaminated with these elements through human activities. Therefore, the United Nations Sustainable Development Goals aim to reduce illness and death resulting from hazardous soil pollution and contamination (Target 3.9), ${ }^{2}$ provide access to safe green and public spaces (Target 11.7), reduce the release of chemicals into soil and their adverse impacts on the human health and environment (Target 12.4), and restore degraded land and soil to achieve a land degradation-neutral world (Target 15.3). Over 1300 active contaminated Superfund sites have been identified by the United States Environmental Protection Agency (US EPA). ${ }^{3}$ The Federal Contaminated Sites Action Plan has identified 4982 active contaminated sites in Canada. ${ }^{4}$ Across Europe, 340,000 
contaminated sites will likely require remediation according to the European Environment Agency. ${ }^{5}$ To facilitate the remediation of these sites and assessment of other sites, agencies often perform a human health risk assessment.

Although humans can be exposed to $\mathrm{Cr}, \mathrm{As}, \mathrm{Cd}, \mathrm{Sb}$, and $\mathrm{Pb}$ in soils through dermal absorption or inhalation, the most significant exposure occurs through incidental ingestion. ${ }^{6}$ One of modeling this ingestion is by using bioaccessibility methods. Bioaccessibility is the amount made available for absorption into the circulatory system by the gastrointestinal fluids, whereas bioavailability is the amount actually absorbed into the bloodstream (Fig. S1). Bioavailability methods are timeconsuming and expensive. In addition, animal subjects (such as pigs, mice, or monkeys) ${ }^{7-9}$ need to be fed contaminated soils to evaluate the uptake and excretion of $\mathrm{Cr}, \mathrm{As}, \mathrm{Cd}, \mathrm{Sb}$, and $\mathrm{Pb}$, which is conducted by analyzing their urine, feces, blood, and sometimes tissues. By contrast, bioaccessibility methods use artificial gastrointestinal fluids to assess the solubility of elements, which theoretically estimates the maximum possible bioavailable concentration. The relevance of such methods is established through a strong correlation between bioaccessibility and bioavailability, i.e., their validation, according to specific criteria. ${ }^{10,11}$

The US EPA employs a method in which samples are agitated for $1 \mathrm{~h}$ in simulated gastric fluids at $37^{\circ} \mathrm{C} .{ }^{12}$ This method is widely used and has been validated for $\mathrm{Pb}^{13}$ and As. ${ }^{14,15}$ It has also been used to predict the relative bioavailability from bioaccessibility measurements. Many studies have also utilized a method based on the United States Pharmacopeia (USP) ${ }^{16}$ that incorporates artificial saliva, gastric, and intestinal fluids. ${ }^{17-19}$ In addition, the Bioaccessibility Research Group of Europe has developed a method called the unified bioaccessibility method (UBM), in which samples are mixed for $1 \mathrm{~h}$ with simulated saliva and gastric fluids, and then subjected to an additional $4 \mathrm{~h}$ of mixing in duodenal and bile fluids. ${ }^{20}$ This method has also been adopted by the International Organization of Standardization (ISO) and validated to assess the oral bioavailability of $\mathrm{Pb}, \mathrm{As}$, and $\mathrm{Cd}$ in an interlaboratory trial. ${ }^{21}$
The methods discussed above use certified reference materials (CRMs) for quality control and validation studies. Some commonly used CRMs for these purposes are produced by the National Institute of Standards and Technology (NIST), specifically NIST 2710, NIST 2710a, and NIST 2711a. Additionally, the British Geological Survey (BGS) produced BGS 102 , a reference material that has been extensively studied for use with the UBM. ${ }^{21-24}$ The published bioavailability results and historic use of these CRMs with validated methods are important for assessing non-validated methods.

All these methods employ inductively coupled plasma mass spectrometry (ICPMS) for elemental analysis because of its high sensitivity, low detection limits, and a large linear dynamic range. ${ }^{25}$ Although ICPMS can be sensitive to matrix effects and spectroscopic interferences,${ }^{26}$ flow injection (FI) can reduce these matrix effects, ${ }^{27}$ and inert $(\mathrm{He})$ or reactive $\left(\mathrm{H}_{2}\right)$ gases can react with possible interfering ions in a collision reaction cell or a collision reaction interface (CRI). While these approaches can facilitate analyte detection, they can also lower the sensitivity. ${ }^{28}$

A significant drawback of the aforementioned bioaccessibility methods is that they require a long extraction time prior to ICPMS analysis, which can be avoided by using the continuous online leaching method (COLM). To use the COLM, the sample is placed in a mini-column. Each gastrointestinal fluid is then sequentially pumped through the mini-column and directly to the nebulizer of the instrument. The gastrointestinal fluids and mini-column are then submerged in a water bath maintained at $37^{\circ} \mathrm{C}$ to simulate the average human body temperature. Fig. 1 illustrates the COLM setup with an ICPMS detector and a low-pressure manifold. Since the gastrointestinal fluid is directly sent to the ICPMS instrument, the sample-handling is greatly reduced, which in turn reduces any potential contamination. Additionally, the extracts produce transient time-resolved peaks that provide real-time information on the leaching kinetics of elements and allow for the analysis of multiple gastrointestinal fluids in under $30 \mathrm{~min} .{ }^{17}$ These temporal profiles can allow the identification of different sources of elements, as differential leaching can be observed in real time. ${ }^{17}$ In addition, it allows isotopic source apportionment, which can help

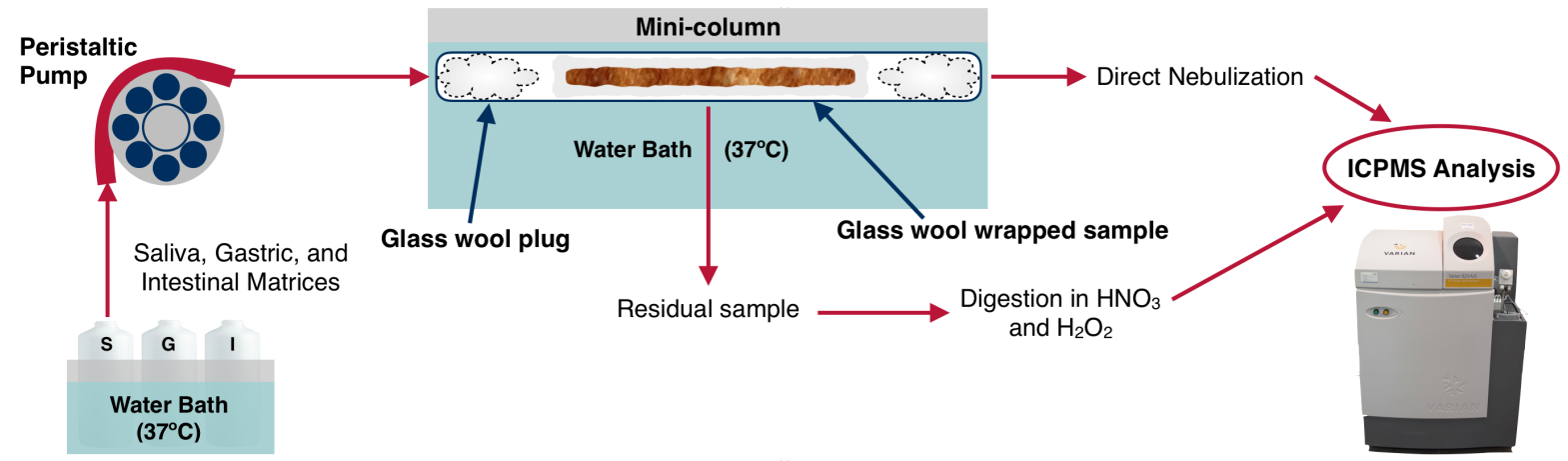

Fig. 1 Schematic representation of the continuous online leaching method (COLM) using a low-pressure manifold. 
identify the source of the contaminants (for instance, from $\mathrm{Pb}$ added to gasoline). ${ }^{29,30}$ The COLM has been used for seafood, ${ }^{18}$ wheat, ${ }^{31}$ bread, ${ }^{32}$ and rice, ${ }^{33}$ however, it has not yet been used for soils, or directly compared to other validated bioaccessibility methods.

Unlike food samples, soils contain refractory components. This study aims to verify whether the COLM can be successfully applied to soils. It also directly compares the COLM with other soil bioaccessibility methods, including the validated US EPA method, USP method, and validated UBM, in order to justify its continued and wide-spread application.

\section{EXPERIMENTAL}

Certified reference materials. Four CRMs, representing soils typically used as controls in bioaccessibility studies, were selected for the study as they have available bioavailability results for comparison: NIST 2710, NIST 2710a, NIST 2711a, and BGS 102. The details of these CRMs can be found in Table S1. They were mixed prior to weighing (0.5-1.0 g, depending on the method). When not in use, the CRMs were stored in the dark at room temperature.

Reagents. All methods used doubly deionized water (DDW) purified to a resistivity of $18.2 \mathrm{M} \Omega \mathrm{cm}$ using either an Arium Pro UV/DI (Sartorius Stedim Biotech, Göttingen, Germany) or MilliQ Direct 8 (Millipore Sigma, Burlington, MA, USA) water purification system. The acids were of American Chemical Society (ACS) reagent grade. Analytical-grade $\mathrm{HCl}$ and $\mathrm{HNO}_{3}$ were used for the UBM. A DST-1000 sub-boiling distillation system (Savillex, Minnetonka, MN, USA) was used for the purification of acids for the aqua regia extraction.

The USP bioaccessibility fluids were prepared in accordance with previous studies ${ }^{17,34}$ and analyzed using the COLM. Enzymes were omitted from the stock solutions and added only on the day of analysis. For saliva stock, $0.896 \mathrm{~g}$ of $\mathrm{KCl}$ (ACS grade; SigmaAldrich), $0.200 \mathrm{~g}$ of KSCN (ACS grade; Sigma-Aldrich), $0.888 \mathrm{~g}$ of $\mathrm{NaH}_{2} \mathrm{PO}_{4}$ (ACS grade; Sigma-Aldrich), $0.570 \mathrm{~g}$ of $\mathrm{Na}_{2} \mathrm{HPO}_{4}$ (ACS grade; Sigma-Aldrich), $0.298 \mathrm{~g}$ of $\mathrm{NaCl}$ (ACS grade; BioShop, Burlington, ON, Canada), $0.072 \mathrm{~g}$ of NaOH (ACS grade; BioShop), $0.200 \mathrm{~g}$ of urea (ACS grade; Sigma-Aldrich), $0.015 \mathrm{~g}$ of uric acid (ACS grade; Sigma-Aldrich), and $0.050 \mathrm{~g}$ of mucin (ACS grade; Sigma-Aldrich) were mixed and diluted to $1 \mathrm{~L}$ with DDW. The $\mathrm{pH}$ was maintained at 6.5 by adding $0.2 \mathrm{~mol} \mathrm{~L}^{-1} \mathrm{NaOH}$. To prepare the gastric stock solution, $2.00 \mathrm{~g}$ of $\mathrm{NaCl}$ and $7.0 \mathrm{~mL}$ of $\mathrm{HCl}$ (ACS grade; Fisher Scientific, Ottawa, ON, Canada) were combined and diluted to $1 \mathrm{~L}$ with DDW and the $\mathrm{pH}$ was maintained at 1.2 using $\mathrm{HCl}$. To prepare the intestinal stock, 6.80 g of $\mathrm{KH}_{2} \mathrm{PO}_{4}$ (ACS grade; Fisher Scientific, NJ, USA) and $77 \mathrm{~mL}$ of $0.2 \mathrm{~mol} \mathrm{~L}^{-1} \mathrm{NaOH}$ were mixed and diluted to $1 \mathrm{~L}$ with DDW after adjusting to $\mathrm{pH} 6.8$ using $\mathrm{NaOH}$. On the day of analysis, enzymes were added by combining $250 \mathrm{~mL}$ of the stock with $0.0729 \mathrm{~g}$ of a-amylase (USP grade; Sigma-Aldrich) for saliva, $0.800 \mathrm{~g}$ of pepsin (USP grade; Sigma-Aldrich) for gastric juice, and $2.50 \mathrm{~g}$ of pancreatin (a mixture of amylase, lipase, and protease) (USP grade; Sigma-Aldrich) for intestinal fluid.

US EPA batch method. Following the standard operating procedure, ${ }^{12}$ three 1 -g aliquots of soil were weighed into $125-\mathrm{mL}$ high-density polyethylene (HDPE) bottles. A simulated gastric fluid was prepared by mixing $30.03 \mathrm{~g}$ of glycine (Reagent Plus Grade; Sigma-Aldrich, Oakville, ON, Canada) in up to $1 \mathrm{~L}$ of DDW at $37^{\circ} \mathrm{C}$ and then adding $\mathrm{HCl}$ (ACS reagent grade; Fisher Scientific, Saint-Laurent, QC, Canada) to obtain a $\mathrm{pH}$ of $1.50 \pm$ 0.05 . Then, $100 \mathrm{~mL}$ of gastric fluid was added to each HDPE bottle and set to rotate end-over-end in an Innova 4230 refrigerated incubator shaker (Eppendorf (previously New Brunswick Scientific), Enfield, CT, USA) at $37{ }^{\circ} \mathrm{C}$ for $1 \mathrm{~h}$ at $60 \mathrm{rpm}$. The sample extracts were filtered through a $0.45-\mu \mathrm{m}$ nylon syringe filter (National Scientific, Claremont, CA, USA) and diluted 100fold with DDW.

Continuous online leaching method (COLM). To overcome the back-pressure experienced with densely packed samples ${ }^{18}$ when 1-g soil aliquots were used, a Spectra SYSTEM P4000 HPLC pump (Thermo Fisher Scientific, Waltham, MA, USA) was used with high-pressure metal mini-columns (emptied guard columns). These mini-columns were $6-\mathrm{cm}$ long with a $1-\mathrm{cm}$ outer diameter and $0.6-\mathrm{cm}$ inner diameter. Two $\sim 0.6-\mathrm{cm}$-diameter disks of Whatman filter paper (Cytiva, Marlborough, MA, USA) were placed at each end of the mini-column filled with $1 \mathrm{~g}$ of soil. During the analysis, the prepared mini-columns were submerged in a $37{ }^{\circ} \mathrm{C}$ water bath (VWR, Mississauga, ON, Canada) and the artificial gastrointestinal fluids (also maintained at $37{ }^{\circ} \mathrm{C}$ ) were pumped through them. Elution took 5-15 min, depending on the gastrointestinal fluid and sample. Eluents from the mini-column were combined with an In internal standard using a Y-connector and nebulized into the ICPMS instrument. External calibration was performed using matrix-matched standards (prepared in each gastrointestinal fluid) and an FI manifold with a $100-\mu \mathrm{L}$ injection loop. As this method was used with US EPA and USP gastrointestinal fluids, each was denoted as COLM-G (for the glycine- $\mathrm{HCl}$ fluid of the US EPA) and COLM-USP, respectively.

Unified bioaccessibility method (UBM). The UBM fluids were prepared in accordance with ISO 17924:2018 ${ }^{20}$ and following a previously reported method. ${ }^{24}$ First, $1 \mathrm{~L}$ of inorganic and organic components of each gastrointestinal fluid was prepared according to the ISO protocol and then combined in a 2-L HDPE bottle at $37^{\circ} \mathrm{C}$. For the batch method, 0.6-g aliquots of soil were combined with $9.0 \mathrm{~mL}$ of saliva in a polycarbonate centrifuge tube and hand shaken for $10 \mathrm{~s}$. Then, $13.5 \mathrm{~mL}$ of gastric fluid was added, and the $\mathrm{pH}$ was adjusted to $1.2 \pm 0.5$. This resulting fluid was then mixed end-over-end in a custom-built water bath for $1 \mathrm{~h}$ at $37^{\circ} \mathrm{C}$. The samples were then centrifuged at $4500 \times g$ for $15 \mathrm{~min}$, decanted, 
and acidified with $9.0 \mathrm{~mL}$ of $0.1 \mathrm{M} \mathrm{HNO}_{3}$ for storage prior to analysis. This made up the "stomach" phase. For the "stomach + intestinal" phase, the same steps were followed as above; however, after rotation for $1 \mathrm{~h}$, the $\mathrm{pH}$ was maintained between 1.2 and 1.5. Then, $27 \mathrm{~mL}$ of the duodenal fluid and $9 \mathrm{~mL}$ of the bile fluid were added, and the $\mathrm{pH}$ was adjusted to $6.3 \pm 0.5$ by adding $37 \%(\mathrm{v} / \mathrm{v})$ $\mathrm{HCl}$ or $1 \mathrm{M} \mathrm{NaOH}$ dropwise. The samples were then mixed for another $4 \mathrm{~h}$ in a water bath at $37^{\circ} \mathrm{C}$. Finally, the $\mathrm{pH}$ was recorded, the samples were centrifuged at $4500 \times g$ for $15 \mathrm{~min}$, decanted, and acidified with $9.0 \mathrm{~mL}$ of $0.1 \mathrm{M} \mathrm{HNO}_{3}$ for storage. All samples were diluted 10 -fold prior to the ICPMS analysis.

For the COLM-UBM, a mini-column was prepared following a method described in previous studies. Low-pressure polytetrafluoroethylene (PTFE) tubing, a peristaltic pump, and a FI manifold ${ }^{31}$ were used. To reduce the back-pressure, $0.6 \mathrm{~g}$ soil was used. Each mini-column had an inner diameter of $7 \mathrm{~mm}$, an outer diameter of $8 \mathrm{~mm}$, and a length of $5 \mathrm{~cm}$. Glass wool (Acros Organics, Fair Lawn, NJ, USA) was cleaned overnight in $10 \%$ (v/v) $\mathrm{HNO}_{3}$, soaked in artificial saliva to matrix-match, dried in air, and then stored in an airtight bag. The mini-columns were prepared by rolling $0.6 \mathrm{~g}$ of soil in glass wool and inserting it into the tubing. A glass wool plug was inserted at each end to secure the sample in place. Three blank mini-columns were prepared by inserting glass wool without any samples. Saliva, gastric juice, duodenal fluid, and bile fluid were sequentially pumped through the mini-columns while continuously monitoring the eluted elements by ICPMS.

Aqua regia extraction. Residual soil CRM from each minicolumn was placed in a PTFE digestion vessel (Savillex) and dried. Additionally, $1 \mathrm{~g}$ of fresh CRM (matching that of the residual) was weighed into a separate digestion vessel to determine the total extractable concentration of each element. Then, $5 \mathrm{~mL}$ of aqua regia $\left(3: 1 \mathrm{v} / \mathrm{v} \mathrm{HCl}: \mathrm{HNO}_{3}\right)$ was made fresh daily and added to each digestion vessel. Aqua regia was also added to one blank vessel without soil. These vessels were sealed and extracted on a hotplate at $\sim 180{ }^{\circ} \mathrm{C}$ for $2 \mathrm{~h}$. The samples were then transferred to Falcon tubes, filtered through a $0.45-\mu \mathrm{m}$ hydrophilic polyvinylidene fluoride filter (Foxx Life Sciences, Salem, NH, USA), and diluted 1000-fold with DDW.

Instrumentation. Samples, excluding those extracted with the UBM, were analyzed using a Varian 820MS quadrupole-based ICPMS instrument equipped with a Pt sampler cone with a 0.9$\mathrm{mm}$ diameter opening and a CRI Ni skimmer cone with a $0.4-\mathrm{mm}$ diameter opening. The samples were introduced into a PTFE concentric nebulizer and a Peltier-cooled Scott-type double-pass spray chamber maintained at $3{ }^{\circ} \mathrm{C}$. Torch alignment was conducted each day using $5 \mu \mathrm{g} \mathrm{L}^{-1}$ of a tuning solution containing $\mathrm{Be}, \mathrm{Mg}, \mathrm{Co}, \mathrm{In}, \mathrm{Ce}, \mathrm{Pb}$, and $\mathrm{Ba}$ in $1 \% \mathrm{HNO}_{3}$. Batch bioaccessibility, total concentrations, and residual data were acquired in the steady-state mode with five points per peak, 20 scans per replicate, and five replicates per sample, whereas the
COLM data were acquired in the time-resolved mode with three points per peak, one scan per replicate, and a dwell time of $80 \mathrm{~ms}$. Other operating conditions are summarized in Table S2. The samples were analyzed with a $5 \mu \mathrm{g} \mathrm{L}^{-1} \mathrm{In}$ internal standard added online using a Y-connector and matrix-matched external calibration.

Samples extracted using the UBM were analyzed with an Agilent 7500 quadrupole-based ICPMS instrument equipped with $\mathrm{Ni}$ cones and an octupole collision reaction system using He and $\mathrm{H}_{2}$ gases for interference reduction. The samples were introduced using a SeaSpray glass concentric nebulizer (AMETEK UK, Leicester, UK) and a quartz Scott-type spray chamber. Torch alignment and tuning were conducted daily using aqueous multielement solutions. Batch UBM samples were analyzed in the steady-state mode and COLM-UBM data were acquired in the time-resolved mode with 50-ms measurements and a sampleuptake rate of $1 \mathrm{~mL} \mathrm{~min}^{-1}$. The samples were analyzed by adding $5 \mu \mathrm{g} \mathrm{L}^{-1}$ of In internal standard to the nebulizer using a T-connector and matrix-matched external calibrations. For the UBM batch method, $25 \mu \mathrm{g} \mathrm{L}^{-1}$ of multi-element standard solution and a major elemental solution were analyzed at the beginning and end of the analysis daily and after every 20 samples.

Data processing. All data were imported into Microsoft Excel (Microsoft, Redmond, WA, USA) for further processing. For the data acquired in the steady-state mode, the samples were internally standard-corrected, converted from count-per-second (c/s) to $\mathrm{mg}$ $\mathrm{L}^{-1}$ using external calibration, blank subtracted, and converted to $\mathrm{mg} \mathrm{kg}^{-1}$ using the dilution factors and original sample masses. For all the data acquired in the time-resolved mode, elution profiles were internal standard corrected by dividing the analyte signal by the In signal point by point, baseline-corrected by taking an average of the baseline on either side of the peak and subtracting from the points along the peak. The peak areas were computed using the following modified trapezoidal equations: ${ }^{35}$

$$
T_{n}=\Delta X\left[\sum_{i=0}^{n} f\left(x_{i}\right)-\frac{f\left(x_{0}\right)}{2}-\frac{f\left(x_{n}\right)}{2}\right]
$$

Where $\Delta X=(b-a) / n, T_{n}$ is the peak area, $f\left(x_{0}\right)$ is the signal at the onset of the peak, $f\left(x_{i}\right)$ is the signal at point $i$ along the peak, $f\left(x_{n}\right)$ is the signal at the end of the peak, $a$ is the first time point of the trapezoid, $b$ is the last time point of the trapezoid, and $n$ is the number of equally spaced trapezoids under the peak. A peak area was obtained for each extraction, which was then converted to $\mathrm{mg}$ $\mathrm{kg}^{-1}$ using external calibration and sample masses.

The percent bioaccessibility was calculated by dividing the total bioaccessible concentration with the total concentration extracted by aqua regia. To compare the data sets, an F test for variance was first performed to compute the appropriate Student's $t$-tests. Next, analysis of variance (ANOVA) was conducted using the XLSTAT add-on in Microsoft Excel. ${ }^{36}$ 
Table 1. Bioaccessible concentrations in $\mathrm{mg} \mathrm{kg}^{-1}$ (mean \pm standard Deviation, $n=3$ ) of $\mathrm{Cr}$, As, $\mathrm{Cd}, \mathrm{Sb}$, and $\mathrm{Pb}$ in the stomach-equivalent phase of all bioaccessibility methods

\begin{tabular}{|c|c|c|c|c|c|c|}
\hline CRM & Method & $\mathrm{Cr}$ & As & Cd & Sb & $\mathbf{P b}$ \\
\hline \multirow{2}{*}{ NIST 2710} & USEPA batch & $0.019 \pm 0.024$ & $195.8 \pm 2.0$ & $19.69 \pm 0.50$ & $3.81 \pm 0.26$ & $4362 \pm 54$ \\
\hline & COLM-G & $0.019 \pm 0.013$ & $195 \pm 27$ & $19.9 \pm 7.0$ & $3.91 \pm 0.55$ & $4500 \pm 2200$ \\
\hline \multirow{2}{*}{ NIST 2710a } & USEPA batch & $0.26 \pm 0.22$ & $309 \pm 41$ & $7.48 \pm 0.98$ & $9.9 \pm 1.1$ & $3165 \pm 540$ \\
\hline & COLM-G & $0.27 \pm 0.46$ & $318 \pm 540$ & $7.5 \pm 6.7$ & $10 \pm 14$ & $3400 \pm 3400$ \\
\hline \multirow{2}{*}{ NIST 2711a } & USEPA batch & $0.072 \pm 0.039$ & $33.00 \pm 0.35$ & $57.5 \pm 1.6$ & $3.94 \pm 0.46$ & $1204 \pm 23$ \\
\hline & COLM-G & $0.072 \pm 0.017$ & $33.8 \pm 6.0$ & $47.5 \pm 4.2$ & $3.89 \pm 0.16$ & $1213 \pm 301$ \\
\hline \multirow{5}{*}{ BGS 102} & USEPA batch & $3.58 \pm 0.28$ & $1.51 \pm 0.61$ & $0.319 \pm 0.058$ & $0.91 \pm 0.14$ & $35 \pm 36$ \\
\hline & COLM-G & $3.6 \pm 3.9$ & $1.50 \pm 0.22$ & $0.32 \pm 0.27$ & $0.92 \pm 0.29$ & $35 \pm 14$ \\
\hline & COLM-USP & $29 \pm 40$ & $4.5 \pm 6.1$ & $0.14 \pm 0.18$ & $0.13 \pm 0.18$ & $11.3 \pm 8.7$ \\
\hline & UBM batch & $35.66 \pm 0.65$ & $3.90 \pm 0.22$ & $0.2177 \pm 0.0073$ & $0.0325 \pm 0.0062$ & $17.2 \pm 2.6$ \\
\hline & COLM-UBM & $34.652 \pm 0.033$ & $\begin{array}{c}4.2955 \pm \\
0.0037 \\
\end{array}$ & $0.21787 \pm 0.00021$ & $0.032435 \pm 0.000035$ & $11.535 \pm 0.039$ \\
\hline
\end{tabular}

Table 2. Analysis of variance (ANOVA) and type III sum of squares (SS) between the results from the US EPA batch method, COLM-G, COLMUSP, COLM-UBM, and UBM batch method for $\mathrm{Cr}, \mathrm{As}, \mathrm{Cd}, \mathrm{Sb}$, and $\mathrm{Pb}$, including the number of observations $(n)$, degrees of freedom (DF), coefficient of determination $\left(R^{2}\right)$, mean squares (MS), F statistic $(F)$, and $P$ value $(P)$ associated with the $F$ statistic. The $P$-values in bold indicate a significant $(P \leq 0.05)$ difference in the methods at the $95 \%$ confidence interval

\begin{tabular}{llllll}
\hline & $\mathbf{C r}$ & As & $\mathbf{C d}$ & $\mathbf{S b}$ & $\mathbf{P b}$ \\
\hline $\mathbf{n}$ & 14 & 14 & 14 & 14 & 14 \\
$\mathbf{D F}$ & 9 & 9 & 9 & 9 & 9 \\
$\mathbf{R}^{2}$ & 0.486 & 0.23 & 0.251 & 0.901 & 0.348 \\
$\mathbf{D F}$ & 4 & 4 & 4 & 4 & 4 \\
$\mathbf{S S}$ & 3018 & 27 & 0.073 & 2.46 & 1884 \\
$\mathbf{M S}$ & 755 & 7 & 0.018 & 0.615 & 471 \\
$\mathbf{F}$ & 2.125 & 0.672 & 0.754 & 20.484 & 1.2 \\
$\boldsymbol{P}$ & 0.16 & 0.628 & 0.58 & 0.0002 & 0.375 \\
\hline
\end{tabular}

\section{RESULTS AND DISCUSSION}

Reproducibility with the COLM versus batch methods. All analyte concentrations were above the detection limits (Table S3) that were calculated using three times the standard deviation of the blank signal. The ranges of percent relative standard deviations (\%RSDs) across all elements (Table S4) were $1-130 \%$ for the US EPA batch method, $4-170 \%$ for the COLM-G, $1-110 \%$ for the UBM, 9-64\% for the COLM-UBM, and $74-170 \%$ for the COLM-USP. Mean \%RSDs for each method were $27 \%$ for the US EPA batch method, $66 \%$ for the COLM-G, $130 \%$ for the COLMUSP, $26 \%$ for the UBM, and $29 \%$ for the COLM-UBM. Thus, it appears that the \%RSDs with the COLM using a low-pressure system (COLM-UBM) are generally smaller than those observed with the COLM using a high-pressure system (COLM-G and COLM-USP), even when the same CRM was used. In fact, with the low-pressure system, the average \%RSD for the COLM-UBM is similar to that with the UBM, whereas the range of RSDs is narrower with the COLM-UBM than that obtained with the UBM. In contrast, both the range of RSDs and the mean \%RSD were greater than those obtained using the batch method when a highpressure system was used for the COLM. Given the inherent heterogeneity of soils, better reproducibility was expected with 1$\mathrm{g}$ aliquots for COLM-G and COLM-USP than with 0.5 -g aliquots with COLM-UBM; however, the inverse result was observed. The generally high RSDs with the COLM when using a high-pressure system are thus completely unexpected. We will investigate this topic in a future work.

Stomach-equivalent extractions. A comparison of the bioaccessible concentrations of the stomach-equivalent phases obtained by different methods is shown in Table 1. BGS 102 was the only CRM analyzed by all three methods, as it has been specifically developed for bioaccessibility and was used in the validation of the UBM for $\mathrm{As}, \mathrm{Pb}$, and $\mathrm{Cd}$ bioaccessibility. The stomach-equivalent phase represents the bioaccessible amount in both saliva and gastric fluids. Because the NIST CRMs were previously used for validation of the USEPA method for As and $\mathrm{Pb}$, they were also used for direct comparison with the COLM-G. For the US EPA method (where no saliva is used), the gastric phase is assumed to also extract what would have been extracted by saliva. ${ }^{37}$ With ANOVA, no statistically significant difference was observed between the batch, COLM-G, COLM-USP, and COLMUBM methods for $\mathrm{Cr}, \mathrm{As}, \mathrm{Cd}$, and $\mathrm{Pb}$ (Table 2). However, for $\mathrm{Sb}$, a significant difference was observed. Further investigation into the model parameters (Table 3) indicated significant differences between the methods with different extraction fluids. However, no difference was observed between the US EPA batch and the COLM-G for Sb. Thus, the differences in the method conditions between the US EPA batch and COLM-UBM, COLM-USP, and UBM batches likely explain the different results for Sb. Additionally, none of these methods is validated for $\mathrm{Sb}$ determination, and the certificate of BGS 102 provides no guidance concentration for $\mathrm{Sb}$ (Table $\mathrm{S} 1$ ). In any case, additional 
Table 3. Model parameters for the ANOVA between the results from the COLM-G, COLM-USP, COLM-UBM, UBM batch method and US EPA batch method for Sb, including the Student's $t(t)$ and $P$-value $(P)$ associated with the Student's $t$-test. The $P$-values in bold indicate a significant $(P \leq 0.05)$ difference between the US EPA batch method and the other methods at the $95 \%$ confidence Interval

\begin{tabular}{lccccc}
\hline Method & Value & Standard error & $\boldsymbol{T}$ & \multicolumn{2}{c}{$\begin{array}{c}\text { Lower bound } \\
(\mathbf{9 5 \% )}\end{array}$} \\
\hline COLM-G & 0.007 & 0.142 & 0.052 & 0.96 & -0.313 \\
COLM-UBM & -0.877 & 0.142 & -6.199 & $<0.0001$ & -1.197 \\
COLM-USP & -0.779 & 0.142 & -5.507 & $<0.0001$ & -1.1 \\
UBM batch & -0.877 & 0.158 & -5.544 & -0.0001 & -1.235 \\
US EPA batch & 0 & 0 & & & -0.519 \\
\hline
\end{tabular}

Table 4. Comparison between the COLM-UBM and conventional UBM batch extraction phases, and stomach-phase COLM-UBM and certificate bioaccessibility concentrations in $\mathrm{mg} \mathrm{kg}^{-1}$ (mean \pm standard deviation, $n=3$ ) of $\mathrm{Cr}$, As, Cd, Sb, and Pb in BGS 102 using Student's $t$-test at $95 \%$ confidence interval

\begin{tabular}{|c|c|c|c|c|c|c|}
\hline & & $\mathrm{Cr}$ & As & Cd & Sb & $\mathbf{P b}$ \\
\hline $\begin{array}{l}\text { COLM- } \\
\text { UBM }\end{array}$ & Stomach & $34.652 \pm 0.033$ & $\begin{array}{c}4.2955 \pm \\
0.0037\end{array}$ & $0.21787 \pm 0.00021$ & $0.032435 \pm 0.000035$ & $11.535 \pm 0.039$ \\
\hline UBM batch & Stomach & $35.66 \pm 0.65$ & $3.90 \pm 0.22$ & $0.2177 \pm 0.0073$ & $0.0325 \pm 0.0061$ & $17.2 \pm 2.6$ \\
\hline$t_{\text {calc }}$ & & 2.683 & 3.1501 & 0.034 & 0.023 & 3.712 \\
\hline$t_{\text {table }}$ & & 4.303 & 4.303 & 4.303 & 4.303 & 4.303 \\
\hline \multicolumn{2}{|c|}{ Certificate bioaccessibility } & & $5.4 \pm 2.4$ & & & $13 \pm 6$ \\
\hline \multicolumn{2}{|l|}{$t_{\text {calc }}$} & & 1.782 & & & 0.772 \\
\hline \multicolumn{2}{|l|}{$t_{\text {table }}$} & & 2.131 & & & 2.262 \\
\hline \multirow{4}{*}{$\begin{array}{l}\text { COLM- } \\
\text { UBM } \\
\text { UBM batch }\end{array}$} & Stomach + Intestinal & $56.666 \pm 0.091$ & $\begin{array}{c}6.1631 \pm \\
0.0053\end{array}$ & $0.29223 \pm 0.00031$ & $0.050498 \pm 0.000051$ & $37.34 \pm 0.12$ \\
\hline & Stomach + Intestinal & $2.7 \pm 1.2$ & $2.63 \pm 0.14$ & $0.061 \pm 0.065$ & $0.0839 \pm 0.0040$ & $0.42 \pm 0.20$ \\
\hline & $t_{\text {calc }}$ & 78.099 & 42.42 & 6.111 & 14.521 & 10.336 \\
\hline & $t_{\text {table }}$ & 4.303 & 4.303 & 4.303 & 4.303 & 4.303 \\
\hline
\end{tabular}

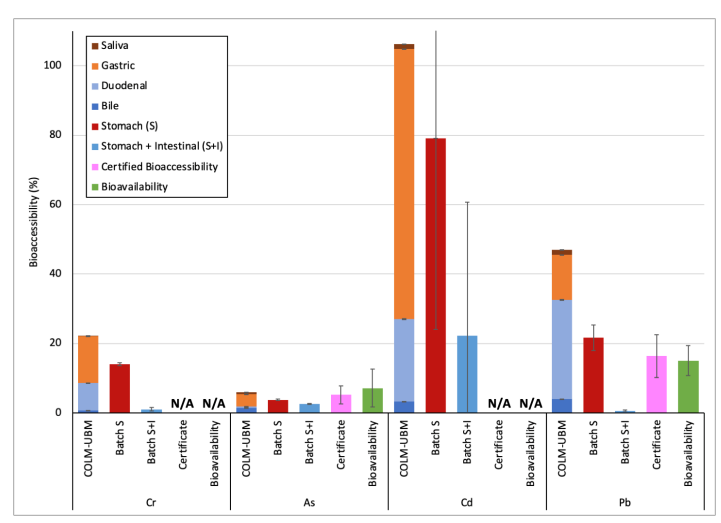

Fig. 2 Percent bioaccessibilities ( \pm standard deviation) of $\mathrm{Cr}, \mathrm{As}, \mathrm{Cd}$, and $\mathrm{Pb}$ in BGS 102 extracted using the COLM-UBM, UBM batch bioaccessibility method $(n=3)$, certificate values, ${ }^{22}$ and bioavailability values $^{40}$ for $\mathrm{As}$ and $\mathrm{Pb}$. No certificate or bioavailability value has been reported for $\mathrm{Cr}$ and $\mathrm{Cd}$ (indicated as "N/A").

information that was not available with batch methods was provided by the COLM. Although not shown here, double peaks that are characteristic of differential sources of elements ${ }^{17}$ resulted in real-time elution profiles from BGS 102 for $\mathrm{Pb}$ when glycine$\mathrm{HCl}$ or gastric fluid was used with the COLM. We will use this information along with $\mathrm{Pb}$ isotope ratios for $\mathrm{Pb}$ source apportionment in another study.

UBM vs. COLM. BGS 102 was selected for this analysis as it was used in the validation of the UBM and developed specifically for bioaccessibility. The concentrations obtained using the conventional UBM batch method and COLM-UBM were compared to the certificate bioaccessibility values (available for $\mathrm{Pb}$ and As) for BGS 102 (Table S5) and presented as percent bioaccessibilities alongside the published bioavailability values ${ }^{38}$ (Fig. 2). During the UBM, the saliva and gastric phases are combined to form the "stomach" phase and the duodenal and bile phases are combined to form the "stomach + intestinal" phase. The "stomach + intestinal" extractions have lower concentrations than the "stomach" phase, as reported in a previous multi-elemental bioaccessibility analysis of BGS 102 (Table S5 and Fig. 2). ${ }^{21,23,39}$ This result can be explained based on the lower solubility of elements at a higher $\mathrm{pH}$ of 6.3 of the duodenal and bile fluids. ${ }^{23}$ For the sum of the saliva and stomach phases during the COLM, no statistically significant difference was observed at the $95 \%$ confidence interval between either the stomach phase of the UBM or certificate bioaccessibility values (Table 4). However, the combined stomach and intestinal fluid evidently differed between the two methods because the sample was exposed to the duodenal and bile phases separately and sequentially with COLM-UBM, which further increased the amount of the analyte released and provided a more conservative estimate of the risk. Although multiple samples can be extracted simultaneously with the UBM, all four gastrointestinal fluids can be extracted in less than $1 \mathrm{~h}$ with the COLM-UBM, while it takes over $5 \mathrm{~h}$ with the UBM.

US EPA vs. COLM. Fig. 3 shows that the COLM-G and US EPA batch bioaccessible concentrations of $\mathrm{Cr}, \mathrm{As}, \mathrm{Cd}, \mathrm{Sb}$, and $\mathrm{Pb}$ in the 


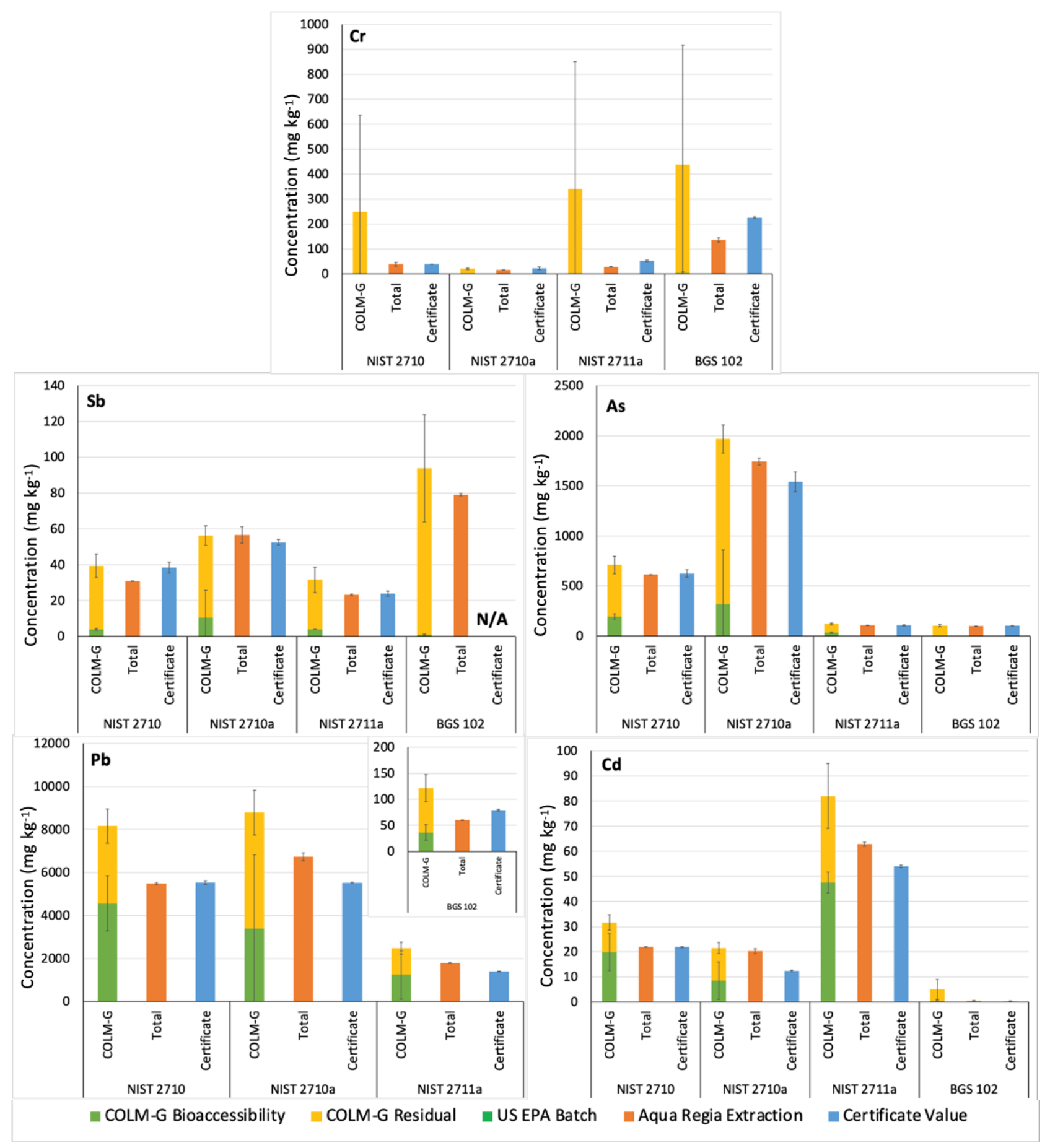

Fig. 3 Comparison of the concentrations (in $\mathrm{mg} \mathrm{kg}^{-1} \pm$ standard deviation, $n=3$ ) of $\mathrm{Cr}$, As, $\mathrm{Cd}, \mathrm{Sb}$, and Pb in NIST 2710, NIST 2710a, NIST 2711a, and BGS 102 using COLM-G, aqua regia extraction, and certificate values.

CRMs are similar despite the COLM-G requiring a fraction of the time needed for the US EPA batch method. The values determined by the two methods did not show any statistically significant difference for any element (Table S6). The matrix spike recovery during the analysis of BGS 102 using the US EPA batch method was $96.6 \%$.
Table 5 compares the percent bioaccessibility for $\mathrm{Pb}$ and $\mathrm{As}$ obtained using the US EPA batch method and COLM-G based on the available control limits ${ }^{12}$ and bioavailability studies ${ }^{40,41}$ for each CRM (as control limits and bioavailability results for $\mathrm{Cr}, \mathrm{Cd}$, and $\mathrm{Sb}$ are unavailable). For both methods, the percent bioaccessibility for $\mathrm{Pb}$ agreed with both the control limits and 
Table 5. Percent bioaccessibilities (mean \pm standard deviation) of As and $\mathrm{Pb}$ with the US EPA batch method and COLM-G compared to control limits and bioavailability (animal) studies for NIST 2710, NIST 2710a, NIST 2711a, and BGS 102

\begin{tabular}{|c|c|c|c|}
\hline CRM & Method & As & $\mathbf{P b}$ \\
\hline \multirow{3}{*}{ NIST 2710} & USEPA batch & $41.5 \pm 3.5$ & $87.9 \pm 2.2$ \\
\hline & COLM-G & $31.9 \pm 4.4$ & $81 \pm 40$ \\
\hline & Control limits ${ }^{\mathrm{a}}$ & $17-60$ & $63-88$ \\
\hline \multirow{5}{*}{ NIST 2710a } & Bioavailability $^{40}$ & $37-50$ & $73-79$ \\
\hline & USEPA batch & $24.3 \pm 3.9$ & $60 \pm 13$ \\
\hline & COLM-G & $18 \pm 31$ & $61 \pm 62$ \\
\hline & Control limits & $24.4-52.5^{(41)}$ & $56-69^{(12)}$ \\
\hline & Bioavailability & $39-45^{(42)}$ & $39-84^{(43)}$ \\
\hline \multirow{3}{*}{ NIST 2711a } & USEPA Batch & $37.2 \pm 6.2$ & $85.5 \pm 8.8$ \\
\hline & COLM-G & $31.6 \pm 5.6$ & $60 \pm 15$ \\
\hline & Control Limits & $N / A^{c}$ & $70-89^{(12)}$ \\
\hline \multirow{5}{*}{ BGS 102} & Bioavailability & N/A & $83-89^{(12)}$ \\
\hline & USEPA Batch & $1.82 \pm 0.90$ & $37 \pm 50$ \\
\hline & COLM-G & $1.48 \pm 0.22$ & $86 \pm 34$ \\
\hline & Control limits $^{\mathrm{b}}$ & $3.0-7.5$ & $8.8-24$ \\
\hline & Bioavailability $^{37}$ & $1.72-12.56$ & $10.7-19.4$ \\
\hline
\end{tabular}

a Derived (see "Control limits for NIST 2710" in Supplemental material); Control limits for BGS 102 using the UBM for informational comparison only; ${ }^{\mathrm{C}} \mathrm{N} / \mathrm{A}=$ No control values, concentrations reportedly too low. ${ }^{12}$

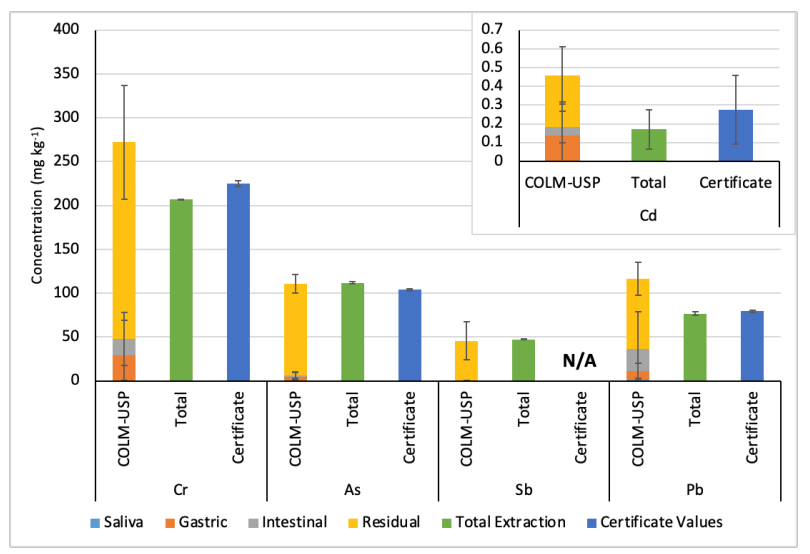

Fig. 4 Comparison of COLM-USP bioaccessibility (including residual phase) of $\mathrm{Cr}, \mathrm{As}, \mathrm{Sb}, \mathrm{Pb}$, and $\mathrm{Cd}$ in BGS 102 with aqua regia extraction values $(n=3)$ and certificate values in $\mathrm{mg} \mathrm{kg}^{-1}( \pm$ standard deviation). There is no certificate value reported for $\mathrm{Sb}$ (indicated as "N/A").

bioavailability ranges for most CRMs. In BGS 102, the higher Pb bioaccessibility (using either method) and lower As bioaccessibility than the reported ranges were likely because the control limits were determined with the UBM, which uses different gastrointestinal fluids.

Verification of the mass balance for the COLM. Fig. 3 compares the sum of bioaccessible plus residual concentrations using the COLM-G to the concentrations obtained by the US EPA batch method, aqua regia extraction, and certificate values. The values determined by the COLM-G sum and aqua regia extraction, COLM-G sum and certificate values, and aqua regia extraction and certificate values according to Student's $t$-test at the $95 \%$ confidence interval were not statistically significant for any of the elements.

A similar comparison was performed using COLM-USP on BGS 102 (Fig. 4). Again, the individual Student's $t$-tests between the COLM-USP sum and the aqua regia extraction concentrations, or the COLM-USP sum and the certificate values did not show any statistically significant difference at the $95 \%$ confidence interval. Additionally, most elements were extracted into the gastric phase, with only $\mathrm{Pb}$ having a significant portion in the intestinal phase. As previously reported for soil, ${ }^{37}$ all elements showed almost no extraction into the saliva phase.

Generally, the COLM could be incorporated into both the US EPA and UBM methods without any discrepancy in bioaccessibility, as demonstrated by ANOVA and Student's $t$-test. The COLM could also provide valuable information about realworld samples through source apportionment ${ }^{17}$ and isotope ratio analysis ${ }^{30}$.

\section{CONCLUSIONS}

The COLM was used to measure the bioaccessibility of Cr, As, Cd, $\mathrm{Sb}$, and $\mathrm{Pb}$ in NIST 2710, NIST SRM 2710a, NIST SRM 2711a, and BGS 102 using gastrointestinal fluids obtained using the US EPA, USP, and UBM methods. With COLM-G, the bioaccessible + residual, total aqua regia extraction, and certificate concentrations were not statistically significantly at the $95 \%$ confidence interval. $\mathrm{Pb}$ bioaccessibility was within the control limits and bioavailability ranges, whereas As was at the lower end of the bioavailability ranges. Mass balance was additionally verified by using the COLM-USP on BGS 102. Most of the elements extracted in the gastric phase; very little extraction was observed in saliva. ANOVA did not yield any statistically significant difference between the COLM and the UBM stomach and US EPA methods. The COLM-UBM agreed with the certificate bioaccessibility values for BGS 102.

Overall, this investigation confirms that the COLM can be incorporated into existing bioaccessibility protocols, particularly for $\mathrm{As}$ and $\mathrm{Pb}$. Although conventional batch methods can be used to simultaneously perform multiple extractions, further refinement of the COLM could allow for a more robust bioaccessibility analysis. We plan to focus on eliminating the cause of degradation in RSD when using a high-pressure system for the COLM in our future work. Additional elements that affect human health, such as $\mathrm{Hg}$, Sn, and $\mathrm{Cu}$, can also be investigated using the COLM. The COLM would be particularly advantageous for $\mathrm{Hg}$, as it provides fewer opportunities to $\mathrm{Hg}$ for adsorption to vessel walls and loss through volatilization. The development of a data processing Excel add-in would further streamline the COLM analysis, allowing for automatic peak integration and conversion from count-per-second measurements to concentrations. Additionally, the kinetic leaching information obtained through the COLM can 
be used for source apportionment, which is not possible with batch bioaccessibility methods. We will analyze soils with known contaminant sources (such as $\mathrm{Pb}$ from gasoline) in our future work to identify different sources of elements and isotopic source apportionment, as it would allow for a more comprehensive soil analysis.

\section{ASSOCIATED CONTENT}

\section{Supporting Information}

The Supporting Information (Table S1-S6, Fig S1, and Control limits for NIST 2710) is available at www.atspectrosc.com/as/home

\section{AUTHOR INFORMATION}

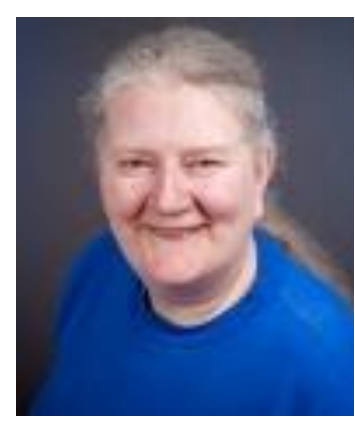

Diane Beauchemin received her Ph.D. in 1984 from Université de Montréal. She is a professor (Full) and Undergraduate Chair at Queen's University. Her research efforts are focused on inductively coupled plasma mass spectrometry (ICPMS) and ICP optical emission spectrometry (OES) from both fundamental and application perspectives, and expanding the range of application of ICPMS/OES to geochemical exploration, risk assessment of food safety, characterization of nanoparticles, and forensic analysis. She has been working as member of editorial board for Atomic Spectroscopy. Diane Beauchemin won the Alan Date Memorial Award (1988) from VG Elemental, the Distinguished Service Award (2001) from Spectroscopy Society of Canada, the Maxxam Award (2017) and Clara Benson Award (2019) from Canadian Society for Chemistry, and the Gerhard Herzberg Award (2018) from the Canadian Society for Analytical Sciences and Spectroscopy. She is author or coauthor of over 100 articles published in peer-reviewed scientific journals.

\section{Corresponding Author}

*D. Beauchemin

Email address: diane.beauchemin@queensu.ca

\section{Notes}

The authors declare no competing financial interest.

\section{ACKNOWLEDGMENTS}

The authors would like to gratefully acknowledge the Natural Sciences and Engineering Research Council of Canada for funding (RGPNM 39487-2018 to DB and RGPIN 2018-04885 to IK). AK also thanks David Patch for training, Queen's University School of Graduate Studies for graduate awards, and Mitacs Globallink for funding (FR38334).

\section{REFERENCES}

1. Health Canada, Federal Contaminated Site Risk Assessments in Canada: Toxicological Reference Values (TRVs), Ottawa (ON), 3.0., 2021.

2. United Nations Department of Economic and Social Affairs, https://sdgs.un.org/goals, (accessed 1 June 2021).

3. US Environmental Protection Agency, https://cumulis.epa.gov/supercpad/cursites/srchrslt.cfm?start=1, (accessed 17 May 2021)

4. Government of Canada, https://www.tbs-sct.gc.ca/fcsirscf/classification-eng.aspx, (accessed 17 May 2021).

5. A. Payá Pérez and N. Rodríguez Eugenio, Status of local soil contamination in Europe, Brussels (BE), 2018.

6. Health Canada, Federal Contaminated Site Risk Assessment in Canada: Guidance on Human Health Preliminary Quantitative Risk Assessment (PQRA), Ottawa (ON), 2021, vol. 3.0.

7. S. W. Casteel, C. P. Weis, G. M. Henningsen, and W. J. Brattin, Environ. Health Persp., 2006, 114, 1162-1171. https://doi.org/10.1289/ehp.8852

8. J. C. Ng, S. M. Kratzmann, L. Qi, H. Crawley, B. Chiswell, and M. R. Moore, Analyst, 1998, 123, 889-892. https://doi.org/10.1039/a707728i

9. S. M. Roberts, J. W. Munson, Y. W. Lowney, and M. V. Ruby, Toxicol. Sci., 2007, 95, 281-288. https://doi.org/10.1093/toxsci/kfl117

10. A. L. Juhasz, N. T. Basta, and E. Smith, Environ. Pollut., 2013, 180, 372-375. https://doi.org/10.1016/j.envpol.2013.05.008

11. Health Canada, Federal Contaminated Site Risk Assessment in Canada: Supplemental Guidance on Human Health Risk Assessment of Oral Bioavailability of Substances in Soil and SoilLike Media - Canada.ca, Ottawa (ON), 2017.

12. US Environmental Protection Agency, Standard Operating Procedure for an In Vitro Bioaccessibility Assay for Lead and Arsenic in Soil, Washington D.C., 2017.

13. US Environmental Protection Agency, Estimation of relative bioavailability of lead in soil and soil-like materials using in vivo and in vitro methods, Washington D.C., 2007.

14. G. L. Diamond, K. D. Bradham, W. J. Brattin, M. Burgess, S Griffin, C. A. Hawkins, A. L. Juhasz, J. M. Klotzbach, C. Nelson, Y. W. Lowney, K. G. Scheckel, and D. J. Thomas, J. Toxicol. Env. Heal. A, 2016, 79, 165-173. https://doi.org/10.1080/15287394.2015.1134038

15. US Environmental Protection Agency, Validation Assessment of In Vitro Arsenic Bioaccessibility Assay for Predicting Relative Bioavailability of Arsenic in Soils and Soil-like Materials at Superfund Sites. Office of Land and Emergency Management. OLEM 9355.4-29, Washington D.C., 2017.

16. The United States Pharmacopeia, in The United States Pharmacopeia and National Formulary, 32nd edn., 2014, p. 344.

17. R. A. Althobiti and D. Beauchemin, J. Anal. At. Spectrom., 2021, 36, 622-629. https://doi.org/10.1039/d0ja00447b 
18. A. Leufroy, L. Noël, D. Beauchemin, and T. Guérin, Anal. Bioanal. Chem., 2012, 402, 2849-2859. https://doi.org/10.1007/s00216-012-5774-4

19. N. W. Sadiq, "Multi-Elemental Risk Assessment of Rice Products Using On-Line Continuous Leaching and Ion Exchange Chromatography Coupled to Inductively Coupled Plasma Mass Spectrometry for the Speciation Analysis of Bio-Accessible Elements", Thesis, Queen's University, Kingston, ON, 2016.

20. International Organization for Standardization, "Soil qualityAssessment of human exposure from ingestion of soil and soil material - Procedure for the estimation of the human bioaccessibility/bioavailability of metals in soil", Report, International Organization for Standardization (ISO), 2018, 1-28.

21. J. Wragg, M. Cave, N. Basta, E. Brandon, S. Casteel, S. Denys, C. Gron, A. Oomen, K. Reimer, K. Tack, and T. Van de Wiele, Sci. Total Environ., 2011, 409, 4016-4030. https://doi.org/10.1016/j.scitotenv.2011.05.019

22. British Geological Survey, "BGS Guidance Material 102 - Ironstone Soil", Report, British Geological Survey (BGS), 2009, vol. 1.

23. E. M. Hamilton, T. S. Barlow, C. J. B. Gowing, and M. J. Watts, Microchem. J., 2015, 123, 131-138. https://doi.org/10.1016/j.microc.2015.06.001

24. BARGE - INERIS, "UBM procedure for the measurement of inorganic contaminant bioaccessibility from solid matrices.", Report, Bioaccessibility Research Group of Europe (BARGE), Nottingham, UK, 2011, 1-10.

25. M. Intawongse and J. R. Dean, TRAC-Trend. Anal. Chem., 2006, 25, 876-886. https://doi.org/10.1016/j.trac.2006.03.010

26. C. Moor, T. Lymberopoulou, and V. J. Dietrich, Microchim. Acta, 2001, 136, 123-128. https://doi.org/10.1007/s006040170041

27. R. Teuma-Castelletti and D. Beauchemin, J. Anal. At. Spectrom., 2020, 35, 2820-2825. https://doi.org/10.1039/d0ja00275e

28. R. A. Althobiti, N. W. Sadiq, and D. Beauchemin, Food Chem., 2018, 257, 230-236 https://doi.org/10.1016/j.foodchem.2018.03.015

29. M. Chu and D. Beauchemin, J. Anal. At. Spectrom., 2004, 19, 12131216. https://doi.org/10.1039/b403215b

30. R. A. Althobiti and D. Beauchemin, J. Anal. At. Spectrom., 2021, 42, 271-277. https://doi.org/ 10.46770/AS.2021.708
31. R. A. Althobiti and D. Beauchemin, J. Anal. At. Spectrom., 2018, 33, 642-648. https://doi.org/10.1039/c8ja00047f

32. R. P. Lamsal and D. Beauchemin, Anal. Chim. Acta, 2015, 867, 917. https://doi.org/10.1016/j.aca.2015.02.047

33. N. S. Horner and D. Beauchemin, Anal. Chim. Acta, 2013, 758, $28-$ 35. https://doi.org/10.1016/j.aca.2012.11.011

34. The United States Pharmacopeia, in The United States Pharmacopeia, United States Pharmacopeia, Rockville, MD, NF XVII., 1990, p. 1788.

35. W. L. Chiou, Critical Evaluation of the Potential Error in Pharmacokinetic Studies of Using the Linear Trapezoidal Rule Method for the Calculation of the Area Under the Plasma LevelTime Curve, 1978, vol. 6.

36. Addinsoft, "XLSTAT statistical and data analysis solution.", Computer Program, New York, NY, 2021.

37. A. L. Juhasz, J. Weber, and E. Smith, J. Hazard. Mater., 2011, 197, 161-168. https://doi.org/10.1016/j.jhazmat.2011.09.068

38. H. B. Li, H. Ning, S. W. Li, J. Li, R. Y. Xue, M. Y. Li, M. Y. Wang, J. H. Liang, A. L. Juhasz, and L. Q. Ma, J. Toxicol. Env. Heal. A, 2021, 84, 593-607. https://doi.org/10.1080/15287394.2021.1919947

39. S. Denys, J. Caboche, K. Tack, G. Rychen, J. Wragg, M. Cave, C. Jondreville, and C. Feidt, Environ. Sci. Technol., 2012, 46, 62526260. https://doi.org/10.1021/es3006942

40. I. Koch, K. J. Reimer, M. I. Bakker, N. T. Basta, M. R. Cave, S. S. Denys, M. Dodd, B. A. Hale, R. Irwin, Y. W. Lowney, M. M. Moore, V. Paquin, P. E. Rasmussen, T. Repaso-Subang, G. L. Stephenson, S. D. Siciliano, J. Wragg, and G. J. Zagury, J. Environ. Sci. Heal. A, 2013, 48, 641-655. https://doi.org/10.1080/10934529.2013.731817

41. US Environmental Protection Agency, IN VITRO BIOACCESSIBILITY REFERENCE MATERIALS FOR LEAD and ARSENIC ROUND ROBIN STUDY REPORT, Washington D.C., 2017

42. US Environmental Protection Agency, Compilation and Review of Data on Relative Bioavailability of Arsenic in Soil, Washington D.C., 2012

43. S. W. Casteel, D. Genny Fent, D. Lee Myoungheon, W. J. Brattin, and P. Hunter, Relative Bioavailability of Arsenic and Lead in the Nist 2710a Soil Standard, Src Tr-09-0951, 2010. 